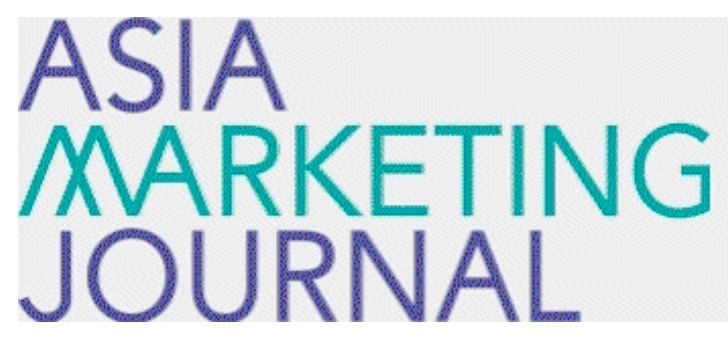

ASIA MARKETING JOURNAL

Volume 23 | Issue 3

Article 2

November 2021

\title{
Authentic Information on the Back Label of Wine Bottle
}

\author{
Beomjoon Choi \\ College of Business Administration, California State University Sacramento, United States \\ Jaewoo Joo \\ Department of Marketing, College of Business Administration, Kookmin University, \\ designmarketinglab@gmail.com
}

Follow this and additional works at: https://amj.kma.re.kr/journal

Part of the Marketing Commons

\section{Recommended Citation}

Choi, Beomjoon and Joo, Jaewoo (2021) "Authentic Information on the Back Label of Wine Bottle," Asia Marketing Journal: Vol. 23 : Iss. 3 , Article 2.

Available at: https://doi.org/10.53728/2765-6500.1576

This Article is brought to you for free and open access by Asia Marketing Journal. It has been accepted for inclusion in Asia Marketing Journal by an authorized editor of Asia Marketing Journal. 


\title{
Authentic Information on the Back Label of Wine Bottle
}

\author{
Beomjoon Choi ${ }^{a}$, Jaewoo Joo ${ }^{\mathrm{b}, *}$

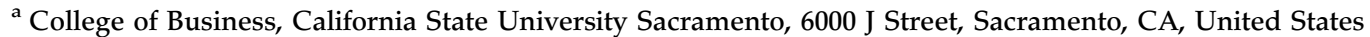 \\ ${ }^{b}$ Department of Marketing, College of Business Administration, Kookmin University, 77 Jeongneung-ro, Seongbuk-gu, Seoul 02707, \\ South Korea
}

\begin{abstract}
This paper investigates whether including authentic information on the back labels of wine bottles enhances consumers' confidence and purchase intentions about wine; it also assesses the moderating role of involvement and knowledge about wine. We conducted two experimental studies. Study 1 generated three findings. First, when the back label had authentic information, subjects showed higher confidence levels. Second, this effect was hold for subjects with low levels of involvement. Finally, we did not observe this effect for subjects with high levels of involvement. Study 2 extended study 1's findings and identified the moderated mediation effect of confidence. The findings highlight the important impact on wine choice of authentic information. However, the findings also suggest that authentic information may not be sufficient to attract people with high levels of involvement and knowledge. This study's findings provide wine producers with practical marketing insights.
\end{abstract}

Keywords: Authenticity, Wine, Confidence, Involvement, Knowledge

A

uthenticity plays a key role in contemporary consumer behavior (Blady 2021; Jung and La 2020). Especially in times of economic crisis and change, consumers prefer products that are either true to themselves and maintain their essential core or appear to be neither counterfeit nor the result of spin or exaggerated claims (Grayson and Martinec 2004). Branding researchers have also actively addressed authenticity. For instance, a September 2009 print advertisement for the Porsche 911 in the New York Times used the headline, "Roots in racing, not posing" to emphasize that the 911 is not posing as something that it is not, that it is what it appears to be-implying that unnamed competitors make exaggerated claims regarding their sports cars and thus are inauthentic (Spiggle, Nguyen and Caravella 2013).

However, researchers have shown surprisingly little interest in examining the effect of authentic information in the context of wine purchase. Purchasing wine typically involves a considerable amount of risk (McCarthy and Spencer 2005) and is also considered a daunting task for many consumers as there are thousands of brand names, numerous grape varieties, regions, wine styles, and a wide range of prices (Johnson and Bruwer 2004; Lockshin and Corsi 2012). It is noteworthy that relatively few consumers possess the skills and expertise to properly assess wine quality. To reduce risk, consumers not only gravitate toward typical labels but also rely on the information on the labels of wine bottles (Charters and Pettigrew 2006). Since more than half of wine consumers $(57 \%)$ use back labels as important sources of information (Charters, Lockshin and Unwin 1999), wine marketers view them as a critical means of communication and purportedly provide useful information to influence consumers' wine choices (Charters et al. 1999; Thomas and Pickering 2003). Previous research has shown that back labels determine the perceived values of wines and affect consumers' wine choices (Chaney 2000).

The present study aims to deepen our understanding of information cues on the back labels of wine bottles by drawing on the literature of authenticity. It

Received 20 August 2021; revised 5 October 2021; accepted 11 October 2021.

Available online 14 November 2021

* Corresponding author.

E-mail addresses: bchoi@csus.edu (B. Choi), designmarketinglab@gmail.com (J. Joo). 
had three specific goals. First, we investigate whether emphasizing authenticity by adding authentic information on the back labels of wine bottles increases purchase intentions. Consumers' growing interest in producer information and the emphasis marketers place on wine label make this an important question. Even though producer information has been used in the food industry (e.g., Spinach sold in Iglo, Europe's frozen foods market), whether such an approach effectively leads to commercial impact has not been rigorously tested. Second, we examine whether consumers' involvement with and their knowledge about wine moderated this effect ( $D$ ' Alessandro and Anthony 2013). This question is important because understanding the ways in which consumers' involvement and knowledge levels influence how they use the different information cues on wine labels prior to making purchase decisions could provide researchers with profound insights. Third, we also examine whether confidence mediates this effect. Many consumers may feel intimidated when selecting wine. To increase wine sales, wine marketers should find ways to enhance consumers' confidence prior to making purchases.

We aim to achieve these three goals by conducting two experiments. For the experiments, we created a hypothetical red wine and graphically presented its back labels to subjects. The experiments were conducted at a state university in Northern California; we recruited 95 undergraduate students for the first experiment and 271 undergraduate students for the second experiment. Our findings were as follows. First, subjects displayed greater confidence in purchasing wine and higher purchase intentions when the back labels included authentic information than when the back labels had no such information or merely included information about wine grape varieties. Second, the effect of adding authentic information on confidence disappeared when subjects were highly involved with wine, and its effect on purchase intentions disappeared when subjects were highly knowledgeable about wine. Third, confidence mediated the effect of authentic information on purchase intentions. Together, these findings suggest that authenticity increases confidence, which, in turn, increases purchase intentions only when consumers are either less involved with or less knowledgeable about wine consumption.

\section{Literature review}

\subsection{Authenticity}

Although authenticity is a multilayered, polysemous concept, it implies that a given item has the authority of its original creator (Spiggle, Nguyen and Caravella 2013). The use of the word as a synonym for genuineness entered the language in the late eighteenth century and the nature of authenticity in consumption remains contested (Ayto 1990). Researchers have described authenticity as original and staged (MacCannell 1973), symbolic (Culler 2007), literal or objective (Beverland, Adam and Michiel 2008), legitimate (Kates 2004), sincere (Beverland 2006), approximate and moral (Leigh, Peters and Shelton 2006), and emergent (Cohen 1988). Although the term authenticity has different meanings, authentic products are believed to have heritage, and products that violate their heritage appear inauthentic. This is because authentic object is viewed as a unique piece that is almost artistic whereas non-authentic one is considered to be replicated to reach wide markets (Leigh, Cara and Jeremy 2006). As such, in the process of creating the authenticity of products, people search for "indexical or iconic cues that would confirm the idea of something placed out of the market, preferably in an utopian past that suggests a long heritage" (Pace 2015, p. 1168).

More specifically, as Grayson and Martinec (2004) noted, brand heritage relies on indexical cues-perceptions that brands have actual connections to the cultural associations that serve as the bases for their heritage. This dimension parallels Gilmore and Pine's (2007) notion of referential authenticity, which they describe as a product of connections to time-situated places, objects, persons, or events. On a related note, Kruger et al. (2004) found that participants believed that a painting that took longer to paint was aesthetically superior and worth more money than one that was painted quickly, even though the two paintings were perceptually identical.

\subsection{Authentic information on the back labels of wine bottles}

Wine is an information-intensive experience product. It has a unique characteristic that sets it apart from other products as consumers generally cannot assess its quality until they consume it (Choi 2017). Therefore, wine purchase decisions are often regarded as complex and involving high degrees of perceived risk and consumers consider not only their own experience and knowledge but also various types of information (Lacey, Bruwer and Li 2009). Among the various type of information they consider, research has shown that back labels influence consumers' wine choices (Annunziata et al. 
2015; Kelley, Hyde and Bruwer 2015; Mantonakis et al. 2014).

Although the back labels of the wines include numerous information regarding wine including regions of origin, vintages, grape varieties, and how the wines are blended, some wines add authentic information on their back labels-information regarding founders to highlight the heritage of wine. The inclusion of such information on back labels is quite rare, generally limited to a few prestigious wines such as Opus One and Dominus. The back label of Opus One, for instance, says the wine is produced and bottled by Robert Mondavi and Baron Philippe De Rothschild. The back label of Dominus features a sketch of the winemaker, Christian Moueix, and his signature from the debut vintage produced between 1983 and 1990. Given that the founders of these wineries have built reputations for high quality wines over several decades, the inclusion of this information on back labels likely leverages reputation or heritage to signal high quality.

This raises an interesting question: could this strategy work for wineries without such reputations, given that references to unknown founders may convey little information to consumers about the wine? Borrowing an insight from a study about business owners, we predict that the same effect would occur. Widely known successful founders (e.g., Steve Jobs and Jeff Bezos) helped create and maintain positive attitudes toward their brands (Pace 2015). Interestingly, even though consumers may not trust small business owners to the extent that they trust well-known CEOs, the presence of such information is found to reduce consumers' perceived risk (Choi, Rosen and La 2012). We argue that information regarding founders functions as an authenticityrelated cue and thereby signals legitimacy and originality. Indeed, we posit that authentic information would increase consumers' confidence. In other words, we predict that consumers would consider authentic information more critical than grape information, meaning they would be more confident and more likely to purchase wines that include authentic information on their back labels. We therefore develop the following hypothesis:

H1: Consumers will be more confident in buying wine when the back label includes authentic information.

\subsection{Involvement}

The impact of authentic information on back labels, however, may depend on the extent of consumers' involvement with wine. Involvement represents the importance or relevance consumers perceive in a product based on their needs, values, and interests. Research has shown that it plays a pivotal role in wine purchase decisions (D' Alessandro and Anthony 2013).

Several prior studies focusing on the impact of wine involvement on consumers' wine decision making suggest that low involvement consumers tend to consider various information to reach their own subjective decisions whereas high involvement consumers consider objective information exclusively to reach an objective decision. For instance, when simulated wines were provided with price, region, brand, and awards, less involved wine drinkers focused on price and awards individually. However, highly involved wine drinkers combined attributes in a more complicated way to make objective decisions. Further, when asked to conceptualize wine quality, less involved wine drinkers rely on subjective, sensory dimensions such as flavor and smoothness whereas highly involved wine drinkers tend to rather objective, cognitive dimensions such as interest or complexity (Charters and Pettigrew 2006).

Note that authenticity is subjective rather than objective. This is primarily because authenticity has a rich nature and various definitions. For instance, in contrast to the common belief that mass-marketed brands cannot be authentic, Kates (2004) argues that "the authentic may be potentially located in select mass-marketed brands" (p. 463). Therefore, even McDonalds' could be authentic for some people who believe easy access of this brand as an authentic aspect, supporting that mass-marketed brands can be authentic (Beverland 2006).

We therefore predict that back label information would not affect highly involved consumers, whereas less involved consumers would likely depend heavily on back label information in making their choices. This is because only less involved consumers will consider authentic information on back labels critical and therefore only they will become more confident (Barber et al. 2006). By contrast, highly involved consumers are more likely to use more complex information cues and seek to make more informed selections to satisfy their needs. They are highly likely to ignore authentic information because it is subjective. We therefore develop the following hypothesis:

H2a: Less involved consumers will be more confident in buying wine when the back label 
includes authentic information; this will not be the case for highly involved consumers (See Fig. 1).

\subsection{Knowledge}

The impact of authentic information on back labels may also depend on the extent of consumers' knowledge about wine. Product knowledge refers to the extent of a consumer's expertise and familiarity with a product (Alba and Hutchinson 1987). It is considered an important indicator of involvement (Charters and Pettigrew 2006). In general, consumers with different levels of product knowledge develop schema differentially, attend to different types of information, and use the same information in different manners (Raju, Lonial and Glynn Mangold 1995). Research has shown that experts have a greater understanding of products, are better acquainted with related information cues, and use these cues more efficiently when evaluating and selecting products than novices (Selnes and Troye 1989). More specifically, novices use surface differences as bases for decision making and engage in simple evaluative judgments based on prior evaluations or simplistic criteria such as image-based cues (Kim et al. 2015). On the other hand, experts use cues only when they are relevant to a product or when they are consistent with their past experiences of the product (D'Alessandro and Anthony 2013).

Based on research examining differences between novices and experts, we expected that the two groups would place different weight on authentic information on back labels. Because authentic information tends to be subjective, novices are likely to respond more positively to such information than to information about wine grapes, meaning they tend to place a heavy weight on such information. Experts, on the other hand, are not likely to weigh such informational cues in this way. Experts process information more comprehensively and make more refined judgments (Maheswaran and Sternthal 1990); consequently, they are likely to recognize that authentic information, which is rather subjective, provides less insight into wine quality than information about wine grapes. In other words, high knowledge consumers are likely to think that the authentic information on back labels provides little insight regarding wine quality, whereas low knowledge consumers may find such information critical and therefore be more willing to purchase wines with back labels that include authentic information as opposed to those that include information regarding wine grapes. In a similar vein, Chaney (2000) argued that wine labels are relevant to the decision-making process only for infrequent wine drinkers, which strengthens our reasoning. Therefore, we develop the following hypothesis:

$\mathrm{H} 2 \mathrm{~b}$ : Less knowledgeable consumers will be more likely to purchase wine when the back label includes authentic information; this will not be the case for highly knowledgeable consumers.

\subsection{Confidence}

Confidence is important in consumers' wine purchase decisions as enhanced self-confidence regarding wine selection increases wine purchases (Olsen, Thompson and Clarke 2003). Gluckman (1990) noted that self-confidence plays a key role in wine purchases because consumers tend to be intimidated when purchasing wine and therefore often use any available information to reduce the stress associated with wine purchases. Barber, Almanza, and Donovan (2006) argued that consumers with little knowledge about wine tend to use easily available information to increase their selfconfidence and reduce risk, whereas consumers with extensive knowledge about wine rely more on their own experiences or complex information. Therefore, we predict that the effect of back label information on purchase intentions would depend on consumers' knowledge, which would be mediated by confidence. Thus, we expect that back labels with authentic information would increase the confidence of low knowledge consumers, which, in turn, would increase their purchase intentions. However, we do not

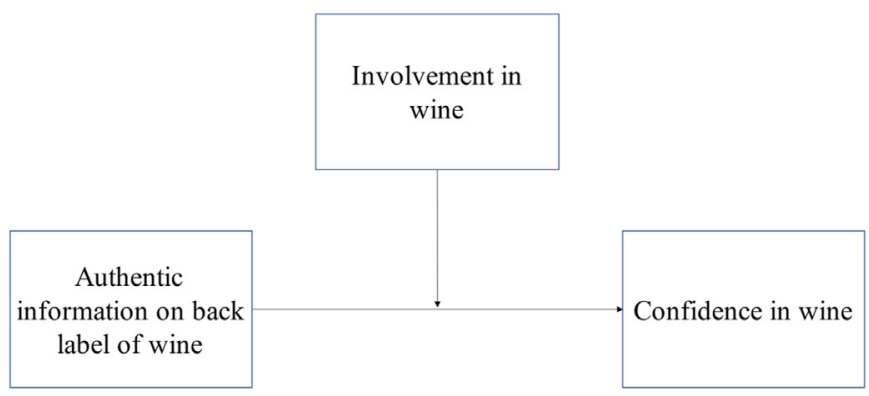

Fig. 1. Conceptual framework of $\mathrm{H} 1$ and $\mathrm{H} 2 a$. 
expect this pattern to hold for high knowledge consumers. We therefore predict the following:

H3: Consumers' knowledge will moderate the effect of authentic information on back labels on purchase intention, and confidence will mediate this moderating effect (See Fig. 2).

\section{Study 1}

\subsection{Objective}

In study 1, we tested two hypotheses: whether authentic information on back labels increases consumers' confidence regarding wine purchases (H1) and whether involvement moderates this effect (H2a). We predicted that (1) subjects would have higher levels of self-confidence when back labels included authentic information than when they did not include such information and that (2) this effect would only manifest among less involved subjects. Correspondingly, we predicted that the effect of authentic information on confidence would disappear among highly involved subjects.

\subsection{Procedure}

We created a hypothetical red wine namely Operancelli and graphically presented its front and back labels. To test hypotheses 1 and $2 a$, we employed a 2 (Information: no vs. authentic) X 2 (Involvement: low vs. high) between-subjects design. We manipulated only the information of the back labels of wine bottles by including hypothetical authentic information or not. The back label for subjects in the authentic information condition read: "Honoring the winemaking legacy that has earned Operancelli its reputation, we have devoted ourselves to crafting wines of exceptional quality and distinctive style for several decades. Our red wine is named Operancelli in honor of my grandfather, Gaetano Operancelli, who founded our property in 1932." Meanwhile, the back label for subjects in the no information condition included no such information. Note that we focused on manipulating only one piece of information on the back labels and kept the remaining information consistent between the two conditions. For instance, the logos, amounts, and alcohol percentages listed on the front labels, as well as the government warnings and barcodes on the back labels were identical between the two conditions. Next, in each condition, subjects were divided into two groups based on median-split involvement scores. In total, subjects were divided into four different groups.

We measured subjects' levels of confidence prior to making wine purchase decisions having them answer three questions on 7-point Likert scales $(\alpha=.962)$ (Urbany et al. 1997) ("Please indicate the level of confidence that you have in making a purchase decision regarding this wine": not confident vs. confident, uncertain vs. certain, and not sure vs. sure). We also measured subjects' level of involvement by asking them to answer three questions on 7-point Likert scales (In general, I have a strong interest in this product category, this product category is very important to me, and This product category matters a lot to me (strongly disagree vs. strongly agree) (Flynn et al. 1996).

\subsection{Study 1 results}

\subsubsection{Findings}

We recruited 97 subjects from a state university located in Northern California, assigning 46 subjects to the no information condition and the remaining 51 subjects to the authentic information condition. Note that we conducted a test to reduce the chance of that subjects' socio-demographic characteristics would influence their choice behavior in any way. We asked subjects to indicate how often they drank wine (every day, twice a week, once a week, twice a month, less than a month, consumed in the past, never). Wine consumption levels differed, but when we controlled wine consumption by making it a covariate, the interaction effect remained significant. More importantly, subjects were undergraduate students enrolled in courses at the same university,

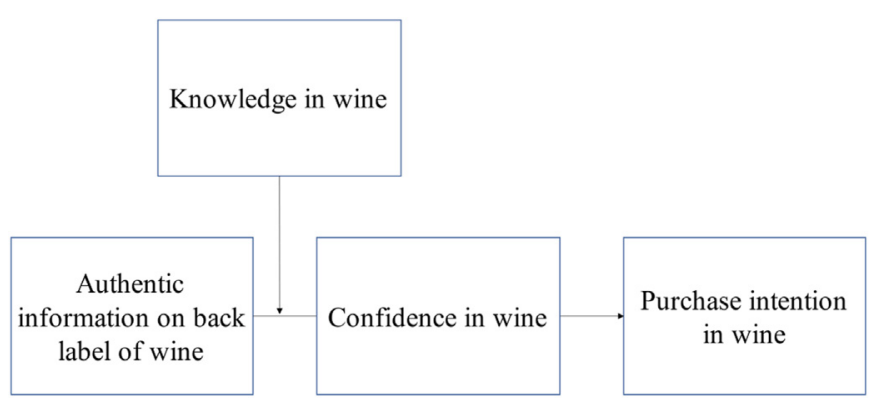

Fig. 2. Conceptual framework of $H 2 b$ and $H 3$. 
so there was no significant difference with respect to age.

Initially, we randomly allocated subjects to one of two conditions (no information vs. authentic information), and in each condition, further divided them into two groups based on a median-split of their indicated involvement scores. We assigned 53 subjects with average involvement scores between 1 and 3 to the low involvement group and the remaining 44 subjects with average involvement scores between 3.33 and 7 to the high involvement group. The average involvement scores in the two groups differed significantly $(F(1,96)=258.157$, $p<.001)$.

As hypothesized, we found that back label information and involvement had an interaction effect on confidence $(F(1,86)=4.119, p=.045)$. More specifically, our analysis showed that confidence varies depending on the presence of authentic information on back labels and involvement moderates this effect. The low involvement subjects showed higher confidence levels in response to the back label that included authentic information than to the back label that included no information $\left(\mathrm{M}_{\mathrm{No}}\right.$, low involvement $=2.46, \mathrm{M}_{\text {Authentic, low involvement }}=4.05 \mathrm{~F}$ $(1,40)=9.448, p=.004)$. On the other hand, we did not observe such an effect among high involvement subjects $\left(\mathrm{M}_{\mathrm{No} \text {, high involvement }}=4.62, \mathrm{M}_{\text {Authenctic, high }}\right.$ involvement $=4.87, F(1,48)=0.455, p>.05)($ Table 1$)$.

\subsection{Discussion}

Our findings demonstrate that authentic information on back labels enhances consumers' confidence, validating the effectiveness of the current marketing practice often observed in the food and beverage industry. We also found that such information increased confidence only for less involved consumers. Although the findings we obtained supported our hypotheses, three issues remained. First, subjects in the authentic information condition received a greater amount of information about the wine than the subjects in the no information condition. Information about the authentic might have increased confidence simply because the quantity of available information in that condition was greater. Second, confidence itself may not matter much for marketers. If adding authentic information merely increases confidence but fails to produce corresponding changes in consumers' behaviors, doing so may have little impact for marketers. Finally, involvement is a relatively broad concept. Although it is critical in decision making, we need to introduce a more narrowly defined concept to deepen our
Table 1. Confidence as a function of back label information and involvement.

\begin{tabular}{llll}
\hline & $\begin{array}{l}\text { No } \\
\text { information }\end{array}$ & $\begin{array}{l}\text { Authentic } \\
\text { Information }\end{array}$ & Statistics \\
\hline Low involvement & 2.46 & 4.05 & $\begin{array}{l}F(1,40)=9.448, \\
\mathrm{p}=.004\end{array}$ \\
High involvement & 4.62 & 4.87 & $\begin{array}{l}F(1,48)=0.455, \\
\mathrm{p}>.05\end{array}$ \\
\hline
\end{tabular}

understanding of the impact of authentic information on consumers' decision making.

To address these three issues, we conducted a second study. In study 2, we compared responses to two different types of information in back labels, measuring both confidence and purchase intentions, and investigating the moderating impact of product knowledge, which is among the strongest indicators of involvement and more clearly defined than involvement (Alba and Hutchinson 1987; Charters and Pettigrew 2006).

\section{Study 2}

In study 2 , we explored a boundary condition and an underlying mechanism of the effect of authentic information on wine purchase behaviors. The key premise of our hypotheses was that wine novices would be less confident than wine experts when making wine purchase decisions. If this is true, wine novices provided with authentic information (vs. grape information) would be more confident, which, in turn, would lead to higher purchase intentions. On the other hand, wine experts would not be influenced by authentic information because they would already be sufficiently confident about their wine purchases. Combining these two hypotheses, we predicted that consumers with low levels of knowledge about wine would be more likely to buy wines with back labels showing authentic information than those showing grape information because the former information would increase confidence and the latter information would not. We expected this effect to disappear for consumers with high levels of knowledge about wine because neither authentic information nor grape information would be likely to increase their confidence. Note that these statements are assumptions based on the premise that authentic information increases confidence for wine novices who lack confidence. In sum, we predicted that label information would influence purchase intentions through confidence only for consumers with low levels of knowledge about wine and that this would not hold for consumers with high levels of knowledge about wine. Study 2 differed from the previous study in two ways. First, 
we measured knowledge in lieu of involvement. Second, we measured both confidence and purchase intention. In so doing, we aimed to provide a more comprehensive explanation of the effect of wine back labels on consumer behavior.

\subsection{Method}

\subsubsection{Design and stimuli}

In the experiment, we employed a 2 (Label: grape vs. authentic) X 2 (Knowledge: high vs. low) between-subjects design. First, we randomly allocated subjects to one of two conditions. Second, we further divided the subjects in each condition into two groups based on a median-split of their knowledge scores. We manipulated the back labels in the following ways. Subjects in the authentic information condition read the same back label used in Experiment 1 ("Honoring the winemaking legacy that has earned Operancelli its reputation, we have devoted ourselves to crafting wines of exceptional quality and distinctive style for several decades. Our red wine is named Operancelli in honor of my grandfather, Gaetano Operancelli, who founded our property in 1932"). Subjects in the grape condition read information about grape varieties ("This wine represents a blend of Cabernet Sauvignon $(60 \%)$, Merlot (35\%), and Cabernet Franc (5\%) grapes grown on our estate"). After being exposed to one of the two labels, subjects answered three questions indicating how confident they were in making wine purchase decisions $(\alpha=.961)$ (Urbany et al. 1997: not confident (1) vs. confident (7), uncertain (1) vs. certain (7), and not sure (1) vs. sure (7)), three questions regarding whether they were going to purchase the wine $(\alpha=.956)$. (Day \& Stafford 1997: Unlikely (1) vs. likely (7), Improbable (1) vs. probable (7), and Impossible (1) vs. possible (7)), and a set of ten multiple choice questions testing their levels of objective knowledge about wine (Hughson $\&$ Boakes 2001). We used the average purchase intention and confidence scores ( $\operatorname{Min}=1$, Max $=7$ ) and counted the total number of correctly answered objective knowledge questions ( $\operatorname{Min}=0, \operatorname{Max}=10$ ). Based on a median split of objective knowledge, we divided subjects into two groups (high vs. low knowledge groups). In sum, we divided subjects into four different groups based on back labels and knowledge levels.

\subsection{Study 2 results}

\subsubsection{Findings}

We recruited 271 subjects from the same university located in northern California. We dropped 21 respondents who did not answer the questions completely and ultimately analyzed a total of 250 responses (104 male, 142 female, and 4 unidentified gender). Their average objective knowledge score was 6.140 (Min objective knowledge $=0$, Max objective knowledge $=10, \mathrm{SD}$ objective knowledge $=2.026$ ).

We predicted that authentic information (vs. grape information) would increase purchase intentions by increasing confidence in wine purchases. Accordingly, we used model 4 of the PROCESS macro for SPSS (Preacher and Hayes 2004) to test whether confidence mediated the effect of back label information on purchase intentions. Bootstrapping analyses using 5000 bootstrap samples revealed a significant mediation. We found that back label information had a significant indirect effect on purchase intentions $(0.240, \mathrm{SE}=.106$, $\mathrm{CI}=[0.038,0.454 \mathrm{e}])($ Tables 2-4).

\subsubsection{Moderated mediation analysis}

We predicted that authentic information (vs. grape information) would increase low knowledge consumers' purchase intentions by increasing their confidence in their wine purchases. On the other hand, we expected that back label information would not have any effect on the confidence or purchase intentions of high knowledge consumers. Accordingly, we used model 7 of the PROCESS macro for SPSS to test whether knowledge moderated the effect of back label information on purchase intentions via confidence. Bootstrapping analyses using 5000 bootstrap samples revealed a significant moderated mediation.

According to the moderated mediation index, confidence had a significant effect $(-0.126$, $\mathrm{SE}=0.052, \mathrm{CI}=[-0.247,-0.039])$. It also showed a significant interaction effect between back label information and knowledge on confidence $(\mathrm{B}=-.278$, $\mathrm{SE}=.101, \mathrm{CI}=[-0.477,-0.078])$, and that confidence successfully mediated the path between back label information and purchase intentions when knowledge was either mean (6.140, $\mathrm{B}=0.231$, $\mathrm{SE}=0.101, \mathrm{CI}=[0.055,0.453])$ or mean minus one standard deviation $(4.114, \mathrm{~B}=0.486, \mathrm{SE}=0.156$, $\mathrm{CI}=[0.218,0.841])$. By contrast, confidence failed to mediate the same path between back label

Table 2. Purchase intentions as a function of back label information and knowledge level.

\begin{tabular}{llll}
\hline & $\begin{array}{l}\text { Grape } \\
\text { information }\end{array}$ & $\begin{array}{l}\text { Authentic } \\
\text { Information }\end{array}$ & Statistics \\
\hline Low knowledge & 3.24 & 4.79 & $\begin{array}{l}F(1,87)=19.34, \\
p=0.00\end{array}$ \\
& & 4.62 & $\begin{array}{l}F(1,112)=0.235, \\
p>0.6\end{array}$ \\
High knowledge & 4.47 & & $p$ \\
& & &
\end{tabular}



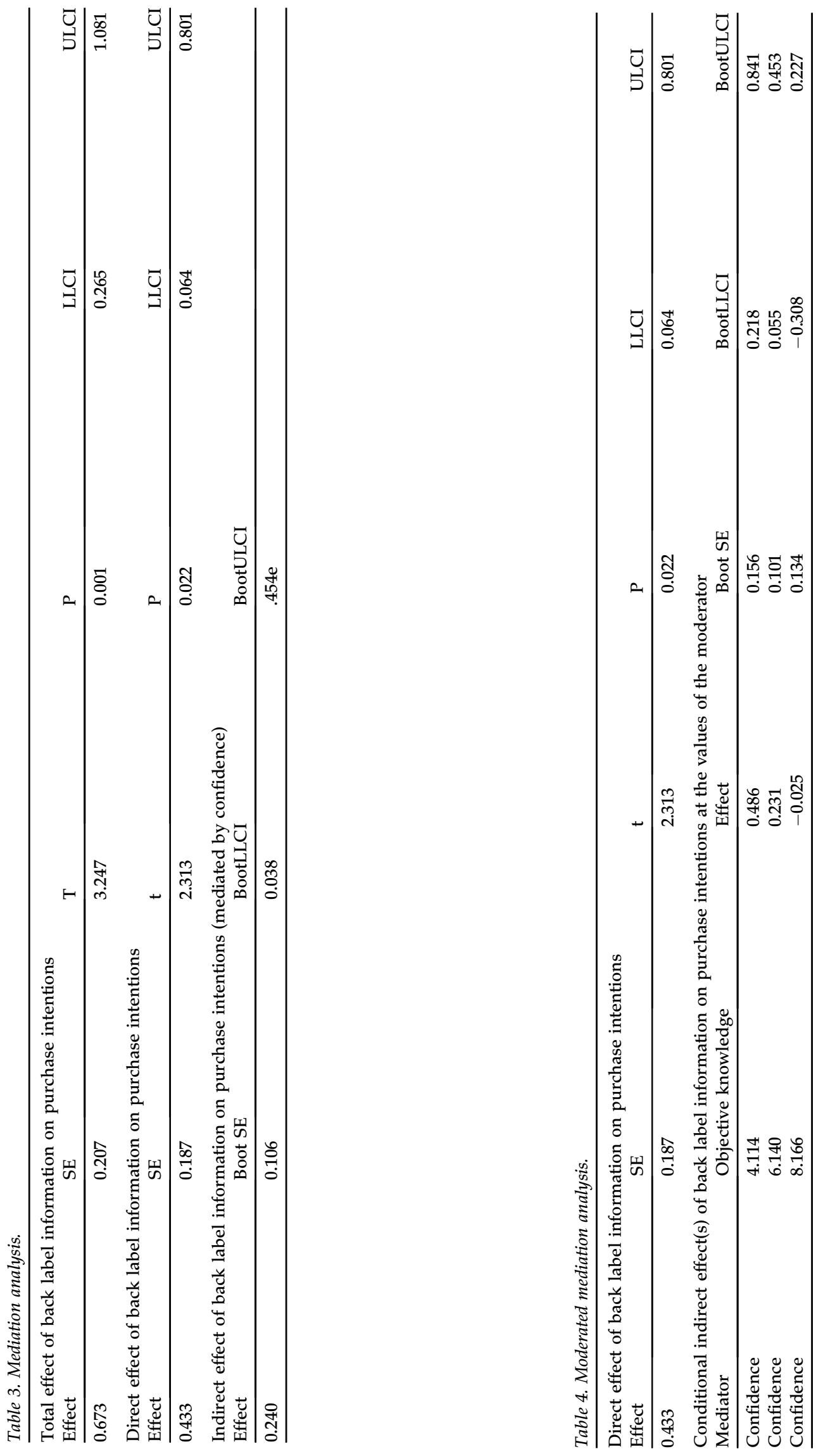
information and purchase intentions when knowledge was mean plus one standard deviation (8.166, $\mathrm{B}=-0.025, \mathrm{SE}=0.134, \mathrm{CI}=[-0.308,0.227])$. In sum, when knowledge was less than or equal to the mean knowledge score (low knowledge), authentic information increased confidence and purchase intentions. However, when knowledge was higher than the mean knowledge score (high knowledge), authentic information failed to increase confidence or purchase intentions.

\subsubsection{Supplementary analysis $(N=201)$}

To acquire a fuller understanding of the mediation effect of confidence and the moderated mediation effect of knowledge, we conducted a median split of knowledge. We dropped respondents whose knowledge scores were the same as the median (Median knowledge $=6$ ) and categorized the remaining 201 respondents into low knowledge $(\mathrm{N}=88)$ and high knowledge $(\mathrm{N}=113)$ groups. The average knowledge scores between the two groups differed significantly $\left(\mathrm{M}_{\text {low }}\right.$ knowledge $=3.875$ vs. $\mathrm{M}$ high knowledge $=7.965, \mathrm{t}(199)=29.172, \mathrm{p}<.001)$.

As hypothesized, the analysis revealed a significant interaction effect between back label information and knowledge $(\mathrm{p}<0.05)$. When subjects were less knowledgeable about wine consumption, authentic information resulted in higher purchase intentions than grape information $\left(\mathrm{M}_{\mathrm{Grape}}\right.$ low knowledge $=3.24, \mathrm{M}$ Authentic, low knowledge $=4.79, \mathrm{~F}(1,87)=19.34, p=0.00)$. However, the back labels had no effect on the purchase intentions of subjects with high levels of knowledge ( $\mathrm{M}_{\text {Grape, high knowledge }}=4.47, \mathrm{M}_{\text {Authentic, }}$ high knowledge $=4.62, \mathrm{~F}(1,112)=0.235, p>0.6)$. Note that our analysis showed that knowledge had a main effect on purchase intentions, which we did not hypothesize. Highly knowledgeable subjects had higher purchase intentions than less knowledgeable subjects ( $M$ low knowledge $=4.05, \mathrm{M}$ high knowledge $=4.55, \mathrm{~F}(1$, $197)=5.10, p=0.025)$. Confidence may explain these unexpected findings-highly knowledgeable subjects tend to be more confident, making them more likely to buy wine. We discuss this relationship in more detail in the mediation analysis section below.

\subsubsection{Purchase intentions}

As hypothesized, we found that back label information and knowledge had an interaction effect on purchase intentions $(F(1,197)=8.902, p=.003)$. The main effects of back label information and knowledge were also significant. When the back label included authentic information, subjects were more likely to purchase wine than when it included grape information $(\mathrm{M}$ Grape $=3.923$ vs. $\mathrm{M}$ Authentic $=4.695, F$ $(1,197)=13.139, p<.001)$. When subjects were highly knowledgeable about wine consumption, they were more likely to buy wine than when they were less knowledgeable $\left(\mathrm{M}_{\text {low knowledge }}=4.053\right.$ vs. $\mathrm{M}_{\text {high }}$ knowledge $=4.546, F(1,197)=4.923, p=.028)$. Note that the interaction between back label information and knowledge drove these two main effects. Low knowledge subjects were more likely to buy the wine with authentic information than the wine with grape information on its back label $\left(\mathrm{M}_{\text {Grape }}=3.238\right.$ vs. $\mathrm{M}$ Authentic $=4.797$, simple effects analysis, mean difference $=1.559, F(1,197)=19.435, p<.001)$. However, this effect disappeared for high knowledge subjects; their purchase intentions were not influenced by back label information $(\mathrm{M}$ Grape $=4.465$ vs. $\mathrm{M}$ Authentic $=4.617$, simple effects analysis, mean difference $=0.151, F(1,197)=0.235, p=.629)$.

\subsubsection{Confidence}

We obtained similar findings regarding the effects of back label information and knowledge on confidence. Their interaction effect was significant ( $F$ $(1,197)=5.062, p=.026)$ and the two main effects were also significant. The subjects were more confident when the back label contained authentic information than grape information $\left(\mathrm{M}_{\text {Grape }}=4.158\right.$ vs. $\left.\mathrm{M}_{\text {Authentic }}=4.657, F(1,197)=5.650, p=.018\right)$. More knowledgeable subjects were also more confident than less knowledgeable subjects ( $\mathrm{M}_{\text {low }}$ knowledge $=4.110$ vs. $\mathrm{M}$ high knowledge $=4.664, F$ $(1,197)=6.006, p=.015)$. Again, the interaction effect mainly drove the two main effects. Low knowledge subjects were more confident when they were exposed to the authentic information than the grape information $(\mathrm{M}$ Grape $=3.540$ vs. $\mathrm{M}$ Authentic $=4.630$, simple effects analysis, mean difference $=1.091, F(1,197)=9.527, p=.002)$. Meanwhile, we found no interaction effect for high knowledge subjects $(\mathrm{M}$ Grape $=4.648$ vs. $\mathrm{M}$ Authentic $=4.678$, simple effects analysis, mean difference $=0.030, F(1,197)=0.009, p=.924)$.

\subsubsection{Mediation analysis}

We conducted a mediation analysis following Baron and Kenny (1986). For low knowledge subjects $(\mathrm{N}=88)$, confidence partially mediated the effect of back label information on purchase intentions (1.559, $t=4.398, p<.001->0.881, t=2.983, p<.001)$. In this group, back label information influenced confidence (1.091, $t=3.092, p=.003)$ and confidence influenced purchase intentions $(0.621, t=7.249, p<.001)$. In contrast, for high knowledge subjects $(\mathrm{N}=113)$, back label information influenced neither purchase intentions nor confidence. In this group, confidence only determined purchase intentions $(0.276, t=3.022$, $p=.003$ ). 


\subsection{Discussion}

The results of study 2 demonstrated that the effects of back label information on purchase intentions depend on knowledge ( $\mathrm{H} 2 \mathrm{~b})$, which is mediated by confidence $(\mathrm{H} 3)$. Authentic information increased low knowledge subjects' confidence, which, in turn, increased their purchase intentions. However, we did not observe a similar pattern for high knowledge subjects. In summary, we not only extended the findings obtained in study 1 , but also identified the moderated mediation effect via confidence.

\section{Conclusion}

Consumers rarely have an opportunity to taste wines prior to purchasing them at retail stores. Thus, to reduce perceived risk, many consumers refer to extrinsic cues such as brand, price, award, labeling, wine origin, bottle form or color (Charters, Lockshin and Unwin 1999; Mueller et al. 2010). However, the large number of available cues often overwhelm consumers. This study showed that including authentic information on the back labels of wine bottles enhances consumers' pre-purchase confidence. It is in line with the contemporary findings about the commercial impact of authenticity (Beverland, Adam and Michiel 2008; Beverland and Farrelly 2010; Gilmore and Joseph Pine 2007; Leigh, Cara and Jeremy 2006).

Interestingly, authentic information effectively increased the confidence of consumers with low levels of involvement, but not those with high levels of involvement, indicating that back labels are more likely to influence subjects who have low levels of interest in wine and are therefore more susceptible to such information. However, we did not observe this authentic information effect among subjects with high levels of involvement. When people are highly involved with wine, the information cues available on back labels do not affect their confidence. This might be because highly involved consumers do not consider back labels important information sources or the information on back labels may not be sufficient to increase the confidence of such consumers, whereas the same back label information can be critical for less involved consumers. While the study 1 findings were intriguing, we needed to conduct further research to deepen our understanding of the impact of back label information cues.

In study 2, we investigated the relative importance of two types of information (authentic vs. grape) and the impact of confidence on purchase decisions. In lieu of involvement, we employed product knowledge in study 2 , since product knowledge is more focused than involvement and directly related to decision making. While research has shown that extrinsic cues influence consumers' acceptance of products (Combris et al. 2009), only few studies have separated and analyzed the relative effects of different extrinsic cues on product evaluations (Enneking, Neumann and Henneberg 2007). This is a critical issue because many wine consumers find it difficult to determine which information they should consider prior to making purchases. Among the many available cues, we compared the relative importance of authentic information and grape information. Our analysis showed that authentic information increased the purchase intentions of low knowledge individuals to a greater extent than grape information. However, we found no such difference among high knowledge subjects, suggesting that highly knowledgeable consumers may look for more relevant information that is rarely found on wine labels. Consistent with Chaney (2000), who found that wine labels are only relevant to the decision-making processes of infrequent wine drinkers, our findings suggest that consumers' responses to back label information cues differ based on knowledge level.

Furthermore, we found that confidence serves as a mediator between authentic information on back labels and purchase intentions and that knowledge moderates this mediator. More precisely, for low knowledge subjects, confidence partially mediated the effect of back label information on purchase intentions. In other words, authentic information increases confidence-leading to increased purchase intentions - only among low knowledge consumers. Since most consumers lack confidence when choosing wine, understanding how to boost confidence prior to wine purchases is critical. Our findings suggest that highlighting authentic information on back labels is likely to attract low knowledge consumers, but may not have the same impact on high knowledge consumers. This is because consumers with high knowledge may rely less on back label information cues than their own experiences, or they may look for more relevant information cues (e.g., wine reviews from influential wine critics and wine scores) to make informed decisions.

\subsection{Practical implications and future research recommendations}

This study's findings suggest that wine label designers need to consider including authentic information when creating wine labels. Note that other food manufacturers have utilized this practice. For instance, Iglo, a leader in Europe's frozen foods market, recently added tracking codes to their 
packages of spinach under the name "Woher kommt Ihr Spinat" (Where does your spinach come from) program. Consumers can type in the code on Iglo's website to find out which farm their spinach comes from and the information the website presents includes family photos and blurbs about the specific farmers (e.g., Claus Bernsmann, for example, is 39 years old, has three children and has been farming for Iglo since 1999).

However, it is also important to note that this may not be effective for everyone. Study 1 showed that exposure to authentic information on the back label only increased the confidence of subjects in the low involvement condition. In a similar vein, study 2 showed that only the subjects in the low knowledge condition displayed increased confidence and higher purchase intentions when exposed to authentic information. Practitioners should consider the possibility that wine label information cues may not be sufficient to attract people with high levels of involvement and knowledge. They may need to provide more relevant and complex information to boost confidence and increase purchase intentions among such consumers, since consumers with high levels of involvement and knowledge have a desire and are motivated to process more relevant and/or even complex information prior to making purchases (Hwang et al. 2021; Park 1999). At the same time, wine makers who are mainly interested in attracting wine novices should pay more attention to wine labels. Understanding the different information needs of the two types of wine consumers (high vs. low involvement, high vs. low knowledge) will provide wine producers with practical marketing insights.
One limitation of this research is that we only considered two types of extrinsic cues: grape and founder. To determine the relative importance of extrinsic cues, researchers should consider more extrinsic cues and compare their weights. Second, our findings suggest that the back labels of wine bottles are not effective for high involvement and high knowledge subjects. Researchers should therefore consider examining which wine label elements, if any, effectively increase the confidence and purchase intentions of highly involved and highly knowledgeable consumers. Other information including reviews or scores from trusted sources such as Wine Spectator could play important roles in this regard (Park et al. 2021). Provided that this area of inquiry was beyond the scope of this research, we leave it to future research. Third, we recommend that researchers consider examining the effect of wine labels in a more realistic setting such as an actual wine store. Field experiments or observational studies may provide more insights into the impact of wine labels on consumers' decisions. Finally, we suggest that researchers should pay more attention to equalize the amount of the information provided in two different conditions (e.g., authentic label vs. not authentic label) in the future research. Also, they may need to pay extra care to determine the right "tone" for the authentic label in order to manipulate perceived authenticity of information properly.

\section{Appendix}

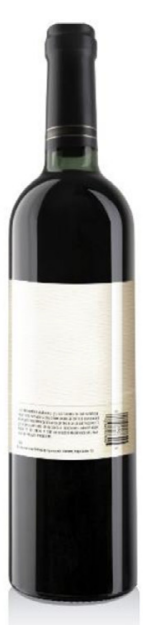

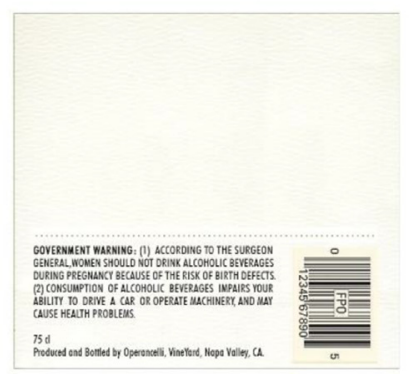

Appendix 1a. Experimental stimuli for Study 1- Label No. 

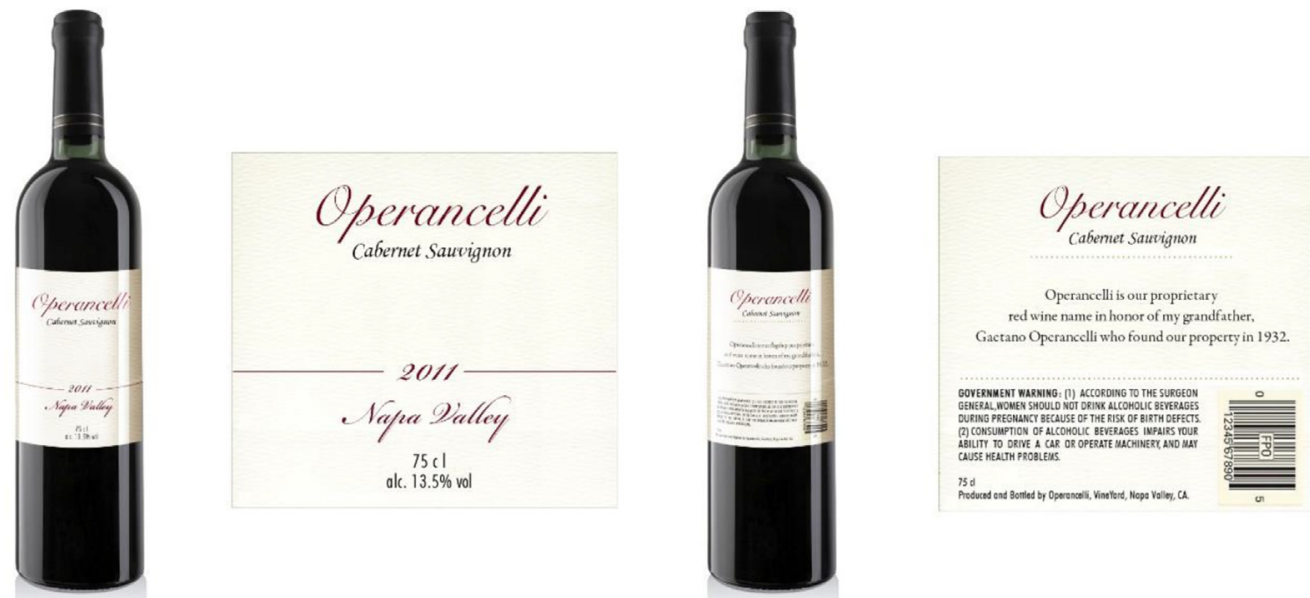

Appendix 1b. Experimental stimuli for Study 1-Label Authentic.

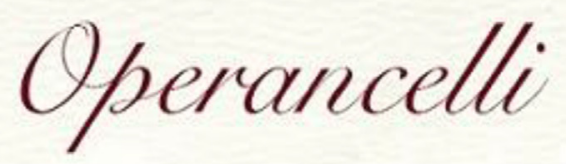

The wine represents a blend of Cabernet Sauvignon (60\%), Merlot (35\%), and Cabernet Franc (5\%) grapes grown on our estate.

GOVERNMENT WARNING: (1) ACCORDING TO THE SURGEON GENERAL,WOMEN SHOULD NOT DRINK ALCOHOLIC BEVERAGES DURING PREG NANCY BECAUSE OF THE RISK OF BIRTH DEFECTS. (2) CONSUMPTION OF ALCOHOLIC BEVERAGES IMPAIRS YOUR ABILITY TO DRIVE A CAR OR OPERATE MACHINERY, AND MAY CAUSE HEALTH PROBLEMS.

$75 \mathrm{~d}$

Produced and Bottled by Operancelli, VineYard, Napa Valley, CA.

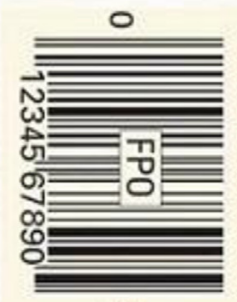

G

Appendix 2a. Experimental stimuli for study 2-Label Grape. 


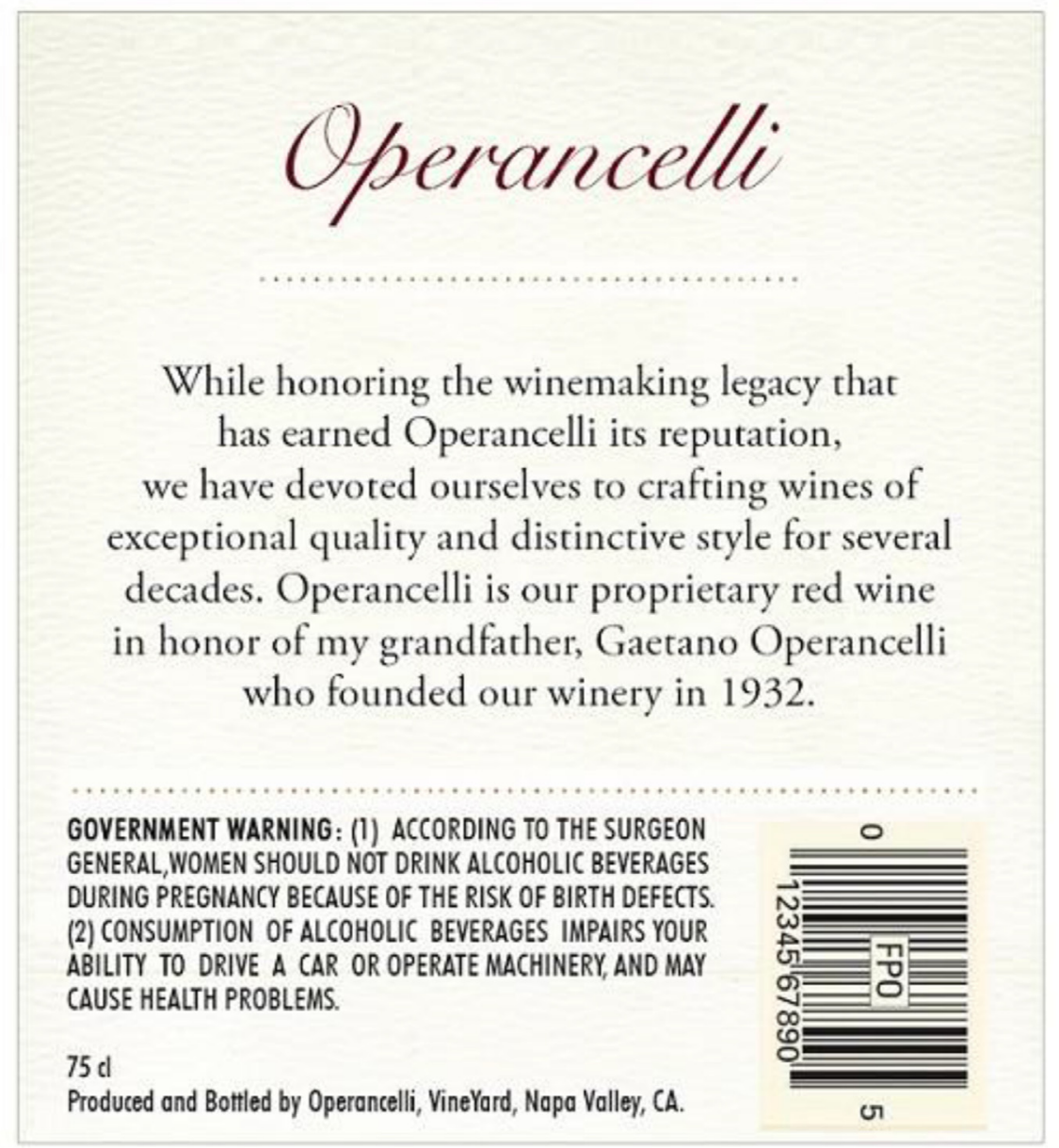

Appendix 2a. Experimental stimuli for study 2-Label Authentic.

\section{References}

Alba, Joseph W. and Wesley Hutchinson (1987), "Dimensions of consumer expertise," Journal of Consumer Research, 13 (4), 411-54.

Annunziata, Azzurra, Eugenio Pomarici, Riccardo Vecchio, and Angela Mariani (2015), "European consumers' interest toward nutritional information on wine labeling: A cross-country analysis," BIO Web of Conferences, 5, Article 04003.

Ayto, John (1990), Dictionary of word origins, Arcade Publishing.

Barber, Nelson A., B. Almanza, and Janis R. Donovan (2006), "Motivational factors of gender, income and age on selecting a bottle of wine," International Journal of Wine Marketing, 18 (3), 218-32.

Baron, Reuben M. and David A. Kenny (1986), "The moderator -mediator variable distinction in social psychological research: Conceptual, strategic, and statistical considerations," Journal of Personality and Social Psychology, 51 (6), 1173.

Beverland, Michael (2006), "The 'real thing': Branding authenticity in the luxury wine trade," Journal of Business Research, 59 (2), 251-8.

Beverland, Michael B., Lindgreen Adam, and W. Vink Michiel (2008), "Projecting authenticity through advertising: Consumer judgments of advertisers' claims," Journal of Advertising, 37 (1), 5-15.

Beverland, Michael B. and Francis J. Farrelly (2010), "The quest for authenticity in consumption: Consumers' purposive choice of authentic cues to shape experienced outcomes," Journal of Consumer Research, 36 (5), 838-56.

Blady, Sharon (2021), "BTS from 'N.O' to 'ON' and BEyond: Innovation in effective mental health messaging and modelling," Asia Marketing Journal, 22 (4), 117-49.

Chaney, Isabella (2000), "The grapevine for New Zealand wine: A multi-dimensional analysis of information dissemination," University of London.

Charters, Steve, Larry Lockshin, and Tim Unwin (1999), "Consumer responses to wine bottle back labels," Journal of Wine Research, 10 (3), 183-95.

Charters, Steve and Simone Pettigrew (2006), "Product involvement and the evaluation of wine quality," Qualitative Market Research: An International Journal, 9 (2), 181-93.

Choi, Kyoung Sung (2017), "Shiraz vs syrah crafting advertising campaign, using sensory images," Asia Marketing Journal, 18 (4), 99-124.

Choi, Beomjoon, Dennis L. Rosen, and La Suna (2012), "The use of portraits and performance statements of service providers in marketing communications," Services Marketing Quarterly, 33 (1), 1-15.

Cohen, Erik (1988), "Authenticity and commoditization in tourism," Annals of tourism research, 15 (3), 371-86.

Combris, P., P. Bazoche, E. Giraud-Héraud, and S. Issanchou (2009), "Food choices: What do we learn from combining sensory and economic experiments?" Food Quality and Preference, 20 (8), 550-7. 
Culler, Jonathan (2007), "The semiotics of tourism," Research Themes for Tourism," American J, 1 (1/2), 127-40.

D'Alessandro, Steven and Pecotich Anthony (2013), "Evaluation of wine by expert and novice consumers in the presence of variations in quality, brand and country of origin cues," Food Quality and Preference, 28 (1), 287-303.

Day, Ellen and Marla Royne Stafford (1997), "Age-related cues in retail services advertising: Their effects on younger consumers," Journal of Retailing, 73 (2), 211-33.

Flynn, Leisa Reinecke, Ronald E. Goldsmith, and Jacqueline K. Eastman (1996), "Opinion leaders and opinion seekers: Two new measurement scales," Journal of the Academy of Marketing Science, 24 (2), 137-47.

Enneking, Ulrich, Claudia Neumann, and Sven Henneberg (2007), "How important intrinsic and extrinsic product attributes affect purchase decision," Food Quality and Preference, 18 (1), 133-8.

Gilmore, James H. and Joseph B. Pine (2007), Authenticity: What consumers really want, Harvard Business Press.

Gluckman, Robert L. (1990), "A consumer approach to branded wines," European Journal of Marketing, 24 (4), 27-46.

Grayson, Kent and Radan Martinec (2004), "Consumer perceptions of iconicity and indexicality and their influence on assessments of authentic market offerings," Journal of Consumer Research, 31 (2), 296-312.

Hughson, Angus L. and Robert A. Boakes (2001), "Perceptual and cognitive aspects of wine expertise," Australian journal of Psychology, 53 (2), 103-8.

Hwang, Sooa, Hyunah Park, Kyunghui Oh, Sangwoong Hwang, and Jaewoo Joo (2021), "Rethinking a designers' rule of thumb: Influence of information seeking and consumption goals on mobile commerce interface design," Journal of Theoretical and Applied Electronic Commerce Research, 16 (5), 1631-47.

Johnson, Trent and Johan Bruwer (2004), "Generic consumer riskreduction strategies (RRS) in wine-related lifestyle segments of the Australian wine market," International Journal of Wine Marketing, 16 (1), 5-35.

Jung, Edward and Suna La (2020), "Wear your heart on your sleeve: Exploring moral identity as a moderator across CSR authenticity, consumer admiration, and engagement in the fashion industry," Asia Marketing Journal, 22 (2), 19-57.

Kates, Steven M. (2004), "The dynamics of brand legitimacy: An interpretive study in the gay men's community," Journal of Consumer Research, 31 (2), 455-64.

Kelley, Kathleen, Jeffrey Hyde, and Johan Bruwer (2015), "U.S. Wine consumer preferences for bottle characteristics, back label extrinsic cues and wine composition: A conjoint analysis," Asia Pacific Journal of Marketing and Logistics, 27 (4), 516-34.

Kim, Yoonjeun, Kiwan Park, Yaeri Kim, and Youngmok Chung (2015), "Comparison of experienced and inexperienced consumers' utilisation of extrinsic cues in product evaluation," Asia Marketing Journal, 17 (3), 105-27.

Kruger, Justin, Wirtz Derrick, Boven Leaf Van, and T. William Altermatt (2004), "The effort heuristic," Journal of Experimental Social Psychology, 40 (1), 91-8.

Lacey, Stephen, Johan Bruwer, and Elton li (2009), "The role of perceived risk in wine purchase decisions in restaurants," International Journal of Wine Business Research, 21 (2), 99-117.

Leigh, Thomas W., Peters Cara, and Shelton Jeremy (2006), "The consumer quest for authenticity: The multiplicity of meanings within the MG subculture of consumption," Journal of the Academy of Marketing Science, 34 (4), 481-93.

Lockshin, Larry and Armando Maria Corsi (2012), "Consumer behaviour for wine 2.0: A review since 2003 and future directions," Wine Economics and Policy, 1 (1), 2-23.

MacCannell, Dean (1973), "Staged authenticity : Arrangements of social space in tourist settings," American Journal of Sociology, $79(3), 589-603$.

Maheswaran, Durairaj and Brian Sternthal (1990), "The effects of knowledge, motivation, and type of message on ad processing and product judgments," Journal of Consumer Research, 17 (1), 66-73.

Mantonakis, Antonia, Brittany Cardwell, Randi Beckett, Eryn Newman, and Maryanne Garry (2014), "The mere presence of a photo on a product label can change taste perception," in Advances in consumer research, J. Cotte and S. Wood, eds. MN: Duluth, 799.

McCarthy, Mary and Henson Spencer (2005), "Perceived risk and risk reduction strategies in the choice of beef by Irish consumers," Food Quality and Preference, 16 (5), 435-45.

Mueller, Simone, Larry Lockshin, Yaelle Saltman, and Jason Blanford (2010), "Message on a bottle: The relative influence of wine back label information on wine choice," Food Quality and Preference, 21 (1), 22-32.

Olsen, Janeen E., Karen J. Thompson, and T.K. Clarke (2003), "Consumer self-confidence in wine purchases," International Journal of Wine Marketing, 15 (3), 40-51.

Pace, Stefano (2015), "Can a commercially oriented brand be authentic? A preliminary study of the effects of a pro-business attitude on consumer-based brand authenticity," Journal of Applied Business Research, 31 (3), 1167-78.

Park, Cheol (1999), "The influence of the consumption ritualization on buying behaviors," Asia Marketing Journal, 1 (3), 12-33.

Park, Young Joon, Jaewoo Joo, Charin Polpanumas, and Yeujun Yoon (2021), "Worse than what I read ?' the external effect of review ratings on the online review generation process: An empirical analysis of multiple product categories using Amazon.com review data," Sustainability, 13 (19), 10912.

Preacher, Kristopher J. and Andrew F. Hayes (2004), "SPSS and SAS procedures for estimating indirect effects in simple mediation models," Behavior Research Methods, Instruments, \& Computers, 36 (4), 717-31.

Raju, P.S., Subhash C. Lonial, and W. Glynn Mangold (1995), "Subjective, objective, and experience-based knowledge: A comparison in the decision-making context," Journal of Consumer Psychology, 4 (2), 153-80.

Selnes, Fred and Sigurd Villads Troye (1989), "Buying expertise, information search, and problem solving," Journal of Economic Psychology, 10 (3), 411-28.

Spiggle, Susan, Hang T. Nguyen, and Mary Caravella (2013), "More than fit: Brand extension authenticity," Journal of Marketing Research, 49 (6), 967-83.

Thomas, Art and Gary Pickering (2003), "The importance of wine label information," International Journal of Wine Marketing, 15 (2), 58-74.

Urbany, Joel E., William O. Bearden, Ajit Kaicker, and Melinda Smith-de Borrero Borrero (1997), "Transaction utility effects when quality is uncertain," Journal of the Academy of Marketing Science, 25 (1), 45-55. 